\section{Response latencies in visual search involving redundant or irrelevant information*}

\author{
GEORGE C. STONE \\ Langley Porter Neuropsychiatric Institute, San Francisco, California 94122
}

Three properties of models for comparison of multiattribute visual stimuli were considered: parallel vs serial processing, efficient vs exhaustive comparisons, and biased vs unbiased acceptance of attributes for processing. Ss performed two comparison tasks, matching-to-sample (M) and identification of odd stimuli $(0)$, with color and form attributes presented singly and in redundant and nonredundant pairings. Analyses of means and of total distributions of response latencies supported the conclusion that parallel and efficient comparisons were the rule, along with a kind of partial selection of attribute to be processed. Ss differed in their relative speed of processing form and color attributes, and these differences accounted for most, but not all, of the differences among them in processing multiattribute stimuli.

Several models may be considered to describe the way in which multiattribute stimuli are processed. Three properties of such models have been extensively discussed by others (e.g., Egeth, 1966; Sternberg, 1967; Hawkins, 1969; Biederman \& Checkosky, 1970); I restate them here, since there may be some readers who are not yet familiar with them. Models can be generated by combinations of three properties of the information processing: (1) "parallel" vs "serial" treatment of multiple attributes; (2) "efficient" (or "self-terminating") processing of stimulus attributes, which is stopped as soon as sufficient information is available for a correct decision, vs "exhaustive" processing; (3) "biasing" (or "selecting") the order in which attributes are to be processed vs "no biasing." Biasing could represent a prior selection of what information would be admitted to the decision channel, regardless of whether serial or parallel preprocessing were the case. It could also refer to a rapid processing of nonselected information. The first sense is the one embodied in the predictions made below. However, as will be seen, the data tend to favor the second.

The three properties are here labeled by distinctive and mnemonic letters to represent the alternative in each processing dimension leading to the fastest responses: "P" for parallel processing, "E" for efficient termination, and " $B$ " for biasing of input. A particular model is designated by appending to each letter an integer between 100 and 0 to indicate the degree to which the more effective property is present. Then "P100, E100, B100" would

*This work was supported by Grants 1-39 and $1-50$ from the California Department of Mental Hygiene. This paper does not reflect the vicws or policies of the California Department of Mental Hygiene. represent the most effective unmixed model of parallel processing, efficient termination, and biased input to the decision channel, while "P0, E0, B0" would represent the other extreme of serial exhaustive and unbiased processing on every trial. ${ }^{1}$

This somewhat awkward labeling device would not be necessary if our task were simply to identify the model that was descriptive of the way that humans process information. However, a growing body of evidence suggests that the applicable model may vary from person to person; it may vary as a function of the specific demands of a task, the context within which the task is set, and the stage of practice. Therefore, our problem is not the identification of a single correct model, but the explication of the variables that determine what model is applicable in a particular situation.

One of the factors that seems most likely to affect strategies in processing multiattribute stimuli is how the attributes are linked. In this study we will be concerned with multiattribute stimuli that are linked redundantly, that is, with perfect correlation between attributes, and nonredundantly, no correlation between attributes, with one attribute specified as relevant and the other irrelevant. In a number of studies, redundant pairings of attributes have elicited faster responses than those obtained when either attribute was presented alone. This result has been found in tasks requiring judgments of difference (Hawkins, 1969; Egeth, 1966; Nickerson, 1967), matching a comparison stimulus to a sample (Stone, 1969), and categorization (Biederman \& Checkosky, 1970).

Some investigations of latencies in categorizing tasks have reported little or no slowing due to the presence of irrelevant information (e.g., Morin, Forrin, \& Archer,
1961; Fitts \& Biederman, 1965). In these experiments it appears that the dimensions most likely to be processed rapidly were the ones that the Es made relevant, so that little slowing would be expected. Imai and Garner (1965) counterbalanced for preference for dimensions and discriminability of attribute values. They reported that even when unpreferred and relatively poorly discriminable stimuli were included, irrelevant attributes had no significant effect on speed of card sorting. In a complex categorization task involving four relevant dimensions, Hodge (1959) found significant increases in response latency as the number of irrelevant dimensions was increased from one to three.

There is little in the literature concerning effects of irrelevant attributes on tasks involving judgments of "same-different" or matching. Egeth (1966) found that judgments of "same" (or membership in a specific criterion class) were faster when stimuli were the same on irrelevant dimensions than when they were not; but he did not directly compare latencies of response to single-attribute stimuli with those to multiple-attribute stimuli.

The uncertainty of the results of previous work may be due in part to the fact that in categorization and "same-different" tasks the time required for processing of the stimulus information is small relative to that involved in the coding and execution of the response. Both of these kinds of tasks present a single stimulus for evaluation and require some sort of stimulus-response coding, such as, "If same, then press left." On the other hand, the matching-to-sample task and the related "oddity" task (in which $S$ is required to find an "odd" or unique stimulus) amplify the effect of the stimulus-comparison phase relative to the response phase by presenting multiple stimuli for evaluation while requiring only a single response. These tasks also minimize the contributions of S-R coding by requiring a maximally compatible response of touching the satisfactory stimulus. This paper reports on the effects of redundant and irrelevant pairings of form and color attributes in these two types of simple visual search tasks.

The predicted latencies for multiattribute tasks generated by six classes of models are shown in Table 1. These models are formed by combining the two extreme values on each of the three properties mentioned above: Parallel processing, efficient termination, and biased input. However, since under exhaustive comparisons all attributes are examined, biasing has no effect. Therefore under E0, 
Table 1

Predictions Concerning Latency Distribution Under Various Classes of Models

\begin{tabular}{|c|c|c|c|c|}
\hline & \multirow[b]{2}{*}{ Task } & \multicolumn{2}{|c|}{ Efficient 100} & \multirow{2}{*}{$\frac{\text { Efficient } 0}{\text { Bias } 100 \text { or } 0}$} \\
\hline & & Bias 100 & Bias 0 & \\
\hline \multirow{3}{*}{ Parallel 100} & CF & Fastest of $\mathrm{C}$ or $\mathrm{F}$ & $\underline{\mathrm{CF}}$ & $\overrightarrow{\mathrm{CF}}$ \\
\hline & $\mathrm{C} / \mathrm{F}$ & $\mathrm{C}$ & $\begin{array}{l}\mathrm{FK}_{\mathbf{K}} \mathrm{C} \\
\mathrm{C} / \mathrm{F}>\mathrm{C}\end{array}$ & $\begin{array}{l}\overrightarrow{\mathrm{CF}} \\
\mathrm{C} / \mathrm{F}>\mathrm{C}\end{array}$ \\
\hline & $F / C$ & $\mathbf{F}$ & $\begin{array}{l}\mathrm{CK}_{\mathbf{K}} \mathrm{F} \\
\mathrm{F} / \mathrm{C}>\mathrm{F}\end{array}$ & $\begin{array}{l}\overline{\mathrm{CF}} \\
\mathrm{F} / \mathrm{C}>\mathrm{F}\end{array}$ \\
\hline \multirow{3}{*}{ Parallel 0} & $\mathrm{CF}$ & Fastest of $\mathrm{C}$ or $\mathrm{F}$ & $\mathrm{C}<\mathrm{CF}<\sum^{.5 \mathrm{C}+.5 \mathrm{~F} \text { or } \mathrm{F}}<\mathrm{CF}<\mathrm{C}$ & $\begin{array}{l}\mathrm{C} . \mathrm{F} \\
\mathrm{CF}>\mathrm{F}\end{array}$ \\
\hline & $\mathrm{C} / \mathrm{F}$ & C & $\begin{array}{l}.5 C+.5(C . F) \\
C / F>C\end{array}$ & $\begin{array}{l}\text { C. } F \\
C / F>F\end{array}$ \\
\hline & $\mathrm{F} / \mathrm{C}$ & $\mathbf{F}$ & $\begin{array}{l}.5 F+.5(C . F) \\
F / C>F\end{array}$ & $\begin{array}{l}\text { C. F } \\
\text { F/C }>F\end{array}$ \\
\hline
\end{tabular}

$\mathrm{B} 100$ and $\mathrm{B} 0$ are pooled, since prediction for them is identical.

The entries in the table refer to distributions of response latencies obtained from tasks using various kinds of stimuli. Single-attribute tasks with color or form stimuli are represented by $\mathrm{C}$ and by $\mathrm{F}$; the redundant pairing of color and form by CF; color stimuli with irrelevant form present by $\mathrm{C} / \mathrm{F}$; and form stimuli with irrelevant color by $F / C$. Specifically, $C$ and $F$ are used here to stand for $F_{c}(t)$ and $F_{f}(t)$, the cumulative relative frequency distributions obtained using color and form stimuli, respectively. The shapes of such distributions are complexly determined by processes that are not considered in this paper.

It is possible to calculate theoretical distributions generated by sampling events from observed empirical distributions. Only two of the distributions entered in the body of Table 1 are empirical; the others are derived from them as follows:

$\mathrm{CF}$ is the cumulative relative frequency distribution of the smaller of two latencies, one drawn from the $\mathrm{C}$ distribution and one from the $F$ distribution. If $C$ and $F$ latencies on a given trial are independent, then the theoretical distribution can be calculated from ${ }^{2} \mathrm{CF}=\mathrm{C}+\mathrm{F}-\mathrm{C} \times \mathrm{F}$. If the latencies in $\mathrm{C}$ and $\mathrm{F}$ are positively correlated, $\mathrm{CF}$ cannot be located exactly. Under many conditions it will lie between the theoretical distribution generated under the assumption of independence and the empirical distribution that has the lower mean latency. If $l_{c}$ and $l_{f}$ are negatively correlated, the CF distribution will have the same bounds until time exceeds the value of the shorter mean latency. 3

$\overrightarrow{\mathrm{CF}}$ is the distribution of the larger of a pair of latencies, one drawn from $C$ and one from $F$. Assuming independence, $1-\overline{\mathrm{CF}}=(1-\mathrm{C})+(1-\mathrm{F})-(1-\mathrm{C}) \mathrm{X}$ $(1-F) \cdot{ }^{4}$ In case of positive correlations, $\overline{\mathrm{CF}}$ probably lies between the are intermediate. For example, in the model P100E100 B50, the predicted latency for the $C / F$ task would be intermediate between $\mathrm{C}$ and $\mathrm{F}_{\mathrm{K}} \mathrm{C}$, and would, in fact, be $.5 \mathrm{C}+.5 \mathrm{~F}_{\mathrm{K}} \mathrm{C}$. The expressions for other intermediate models can be readily calculated.

At this stage in the development of the models, we cannot say precisely what form some of the distributions should take, because we do not know to what extent latencies in processing form and color attributes are correlated over trials. It is possible, however, to state the direction of certain inequalities. These are also shown in Table 1. The predictions in Table 1 can be tested in two ways. The inequalities can be tested by sampling from the various empirical distributions and applying conventional analysis of variance. It is also possible to compare whole empirical distributions with each other, and with theoretical distributions, using the Kolmogorov-Smirnov statistic (Siegel, 1956).

\section{METHOD}

Three male and three female Ss, ranging in age from 9 to 76 years, were given two test sessions per week for 4 weeks, with a minimum of $48 \mathrm{~h}$ between test sessions (age and sex of each $S$ are given in Table 2). Tasks were presented on a console where five Industrial Electronic Engineers display cells (Series 10000) appeared in a horizontal row. The stimuli, centered $3 \mathrm{in}$. apart and approximately $1 \mathrm{in.}$ in diam, are referred to hereafter as $\mathrm{s} 1$ to $s 5$, from left to right. Ss responded by pressing on transparent panels $(\mathrm{r} 1$ to $\mathrm{r} 5)$ that covered the stimulus behind it. A sixth response panel, $r 6$, located 2 in. below $r 3$, had no stimulus associated with it.

The $S$ was allowed to seat himself in a comfortable position in front of the panel. Observed distances from Ss' eyes to the stimuli ranged from 14 to 20 in., corresponding to angular separations of $12 \frac{1}{2}$ and $8 \frac{1}{2}$ deg between adjacent stimuli.

Two types of tasks were used, matching-to-sample $(\mathrm{M})$ and oddity $(\mathrm{O})$. Each type of task was presented using five different stimulus sets: (1) color (C), 1-in. circular patches of red, green, blue, or Table 2 three properties are not limited to the values 100 and 0 , the predicted latencies

Mians Over All Cycles and Sessions

\begin{tabular}{|c|c|c|c|c|c|c|c|c|c|c|c|c|c|}
\hline \multirow{2}{*}{$\begin{array}{l}\text { Sub- } \\
\text { ject }\end{array}$} & \multirow[b]{2}{*}{ Sex } & \multirow[b]{2}{*}{ Age } & \multirow[b]{2}{*}{$\mathrm{n}^{*}$} & \multicolumn{5}{|c|}{ Matching } & \multicolumn{5}{|c|}{ Oddity } \\
\hline & & & & $\mathrm{C}$ & $\mathrm{l}$ & $\mathrm{Cl}$ & $\mathrm{C} / \mathrm{l}^{*}$ & $\mathrm{~F} / \mathrm{C}$ & $C$ & F & $\mathrm{CF}$ & $\mathrm{C} / \mathrm{F}$ & $\mathrm{F} / \mathrm{C}$ \\
\hline 1 & 1: & 9 & 14 & 503 & 598 & 526 & 541 & 647 & 539 & 633 & 580 & 588 & 731 \\
\hline 2 & 1: & 23 & 32 & 506 & 524 & 509 & 505 & 554 & 492 & 531 & 514 & 522 & 595 \\
\hline 3 & 1: & 24 & 32 & 409 & 467 & 418 & 426 & 551 & 440 & 529 & 460 & 462 & 602 \\
\hline 4 & $\mathrm{M}$ & 26 & 32 & 546 & 566 & 552 & 573 & 617 & 592 & 690 & 642 & 641 & 756 \\
\hline 5 & $\mathrm{M}$ & 25 & 32 & 447 & 448 & 470 & 475 & 478 & 505 & 516 & 525 & 550 & 560 \\
\hline 6 & $\mathbf{M}$ & 76 & 28 & 772 & 720 & 775 & 872 & 812 & 901 & 920 & 915 & 1017 & 1015 \\
\hline
\end{tabular}

* Number of block medians on which each mean is based. 
Table 3

Differences (Msec) in Mean Latencies for Selected Pairs of Stimulus Conditions. M stands for matching, 0 for oddity.

Differences

\begin{tabular}{|c|c|c|c|c|c|c|c|c|c|c|c|c|}
\hline \multirow[b]{2}{*}{ Subject } & \multicolumn{2}{|c|}{$\mathrm{I}-\mathrm{C}$} & \multicolumn{2}{|c|}{$\mathrm{CF}-\mathrm{C}$} & \multicolumn{2}{|c|}{$\mathrm{F}-\mathrm{Cl}$} & \multicolumn{2}{|c|}{$\mathrm{C} / \mathrm{l}-\mathrm{C}$} & \multicolumn{2}{|c|}{$\mathrm{I} / \mathrm{C}-\mathrm{F}$} & \multicolumn{2}{|c|}{$\mathrm{F} / \mathrm{C}-\mathrm{C} / \mathrm{F}$} \\
\hline & $M$ & 0 & $\mathbf{M}$ & o & $\mathbf{M}$ & 0 & $\mathbf{M}$ & 0 & $\mathrm{M}$ & $\mathrm{O}$ & $\mathbf{M}$ & 0 \\
\hline $\begin{array}{l}1 \\
2 \\
3 \\
4\end{array}$ & $\begin{array}{l}95^{* *} \\
18 \\
58^{* *} \\
21^{*}\end{array}$ & $\begin{array}{l}94^{* *} \\
39^{* *} \\
89^{* *} \\
99^{* *}\end{array}$ & $\begin{array}{r}23 \\
-1 \\
9 \\
7\end{array}$ & $\begin{array}{l}41^{*} \\
22^{*} \\
20^{*} \\
51^{* *}\end{array}$ & $\begin{array}{l}72^{* *} \\
15 \\
49^{* *} \\
14\end{array}$ & $\begin{array}{l}53^{* *} \\
17 \\
69^{* *} \\
48^{* *}\end{array}$ & $\begin{array}{c}38 \\
3 \\
17 \\
28^{*}\end{array}$ & $\begin{array}{l}49^{*} \\
30^{* *} \\
22^{*} \\
50^{* *}\end{array}$ & $\begin{array}{l}49^{*} \\
30^{* *} \\
84^{* *} \\
51^{*}\end{array}$ & $\begin{array}{l}98^{* *} \\
64^{* *} \\
73^{* *} \\
66^{* *}\end{array}$ & $\begin{array}{r}106^{* *} \\
49^{* *} \\
125^{* *} \\
44^{* *}\end{array}$ & $\begin{array}{r}143^{* *} \\
73^{* *} \\
140^{* *} \\
115^{* *}\end{array}$ \\
\hline $\begin{array}{l}5 \\
6\end{array}$ & $\begin{array}{c}1 \\
-52 * *\end{array}$ & $\begin{array}{l}11 \\
19\end{array}$ & $\begin{array}{c}23^{* *} \\
3\end{array}$ & $\begin{array}{l}20^{*} \\
14\end{array}$ & $\begin{array}{l}-22^{* *} \\
-55^{* *}\end{array}$ & $\begin{array}{r}-9 \\
5\end{array}$ & $\begin{array}{r}28^{* *} \\
100^{* *}\end{array}$ & $\begin{array}{r}45^{* *} \\
116^{* *}\end{array}$ & $\begin{array}{l}30^{* *} \\
92^{* *}\end{array}$ & $\begin{array}{l}44^{* *} \\
95^{* *}\end{array}$ & $\begin{array}{c}3 \\
-60^{* *}\end{array}$ & $\begin{array}{r}10 \\
-2\end{array}$ \\
\hline
\end{tabular}

* $p<.05 ; * * p<.01$ by Newman-Keuls test.

yellow; (2) form (F), square, circle, triangle, plus; (3) redundant color-form (CF), red-plus, blue-circle, green-square, yellow-triangle; (4) color with irrelevant form $(\mathrm{C} / \mathrm{F})$, the four colors with randomly chosen forms superimposed; (5) form with irrelevant color-form $(F / C)$, the four forms against randomly chosen color backgrounds.

On each trial of a matching task the sample was presented in sl (the left-hand stimulus display cell). $S$ pressed $r 6$, which led to the disappearance of the sample and, after a 200 -msec delay (during which the program tape moved to its next position), the appearance of four "comparison stimuli" in $s 2$ through $s 5$. The task was to press the response panel over the stimulus that matched the sample on the critical attribute, or attributes. An incorrect response was recorded but had no effect on the stimulus display. A correct response was followed by the disappearance of the comparison stimuli and the appearance of the sample for the next trial or by a distinctive "block-separator" stimulus that signaled $S$ to stop responding and wait for further instructions. At this time the $\mathrm{E}$ gave information about the task next to be encountered: "Next match color, ignore form" or "Find the odd form."

Each trial of an oddity task began with all display panels dark. $S$ pressed $r 6$, and four stimuli appeared in s2 through $s 5$. Three of the stimuli were identical with respect to the critical attribute or attributes, while one differed. The task was to press on the one that differed.

In both tasks, the target stimuli were chosen by random permutations in such a way that each of the four values of the critical attribute occurred three times in a block, but without further constraint upon sequence. The location of the target was similarly randomized subject to the constraint of equal frequency at each location. In the matching task the nontarget stimuli were a random ordering of the three remaining values on the critical attribute, with no intertrial constraints.

Tasks were presented in blocks of 12 trials ending with the block separator. The five matching and five oddity tasks were randomly permuted in "cycles" within which each task appeared once. Four cycles of tasks were presented in each of the eight testing sessions. (S 1 had only seven sessions and two cycles per session. Data from the first session of S 6 were lost due to equipment failure.) At each response a paper-tape punch recorded the location of the response and the time in milliseconds that separated it from the previous response. Response latencies were adjusted to represent the time from appearance of the stimuli until the selection response was made. Data analyses are based upon only those trials in which the first response was correct. For each block of 12 (after deletion of error trials, occasionally 11 and rarely 10 ) trials, the median latency was determined, and these medians were subjected to analysis of variance. $^{5}$ The total distributions of latencies of initially correct responses were used in other analyses.

\section{RESULTS \\ Analysis of Mean Differences}

Error rates varied from $S$ to $S$ and from task to task, averaging $3 \%$ and never exceeding $12 \%$. There was no consistent tendency for the faster Ss to exhibit higher error rates, and within $S s$ there was a slight tendency for the error rate to be higher in the tasks producing longer latencies. The results to be described therefore cannot be attributed to a speed-accuracy tradeoff

Means of the block medians taken over all cycles and sessions are shown in Table 2. Data from each $S$ were analyzed separately in four-way analyses of variance involving matching vs oddity tasks (task format), stimulus type, sessions, and cycles within sessions, all treated as fixed effects. For five of the six Ss the mean latency of responding in the matching task was significantly shorter than the latency in responding to the oddity tasks. Differences, all significant at the .001 level, ranged from 44 to $163 \mathrm{msec}$, with three of them in the range of 44 to $68 \mathrm{msec}$. S 3 showed only an 11-msec difference overall between the oddity and matching format, and was actually faster in the oddity format after the first session.

The difference between the matching and oddity task formats interacted significantly with differences among stimuli in the data of four of the six Ss and with the differences over sessions in the data of five of the six Ss. It therefore seemed preferable to do further analyses for the two task formats separately.

Following the overall tests of significance of the stimulus effect, which in all cases were significant beyond the .001 level, the Newman-Keuls test was used to compare differences between means for individual stimuli (Winer, 1962). Certain selected differences relevant to the hypotheses of this experiment are shown in Table 3. The first two columns of this table indicate that responses to form were usually slower than those to color. This was true of four of the six Ss in matching and all six Ss in oddity, although a few of the differences fell short of statistical significances. Thus, in considering hypotheses about speeds of the multiattribute tasks relative to the single-attribute tasks, we will have to differentiate between those Ss who responded faster to color than to form ("color-biased" Ss) and those who did not.

The next four columns of Table 2 present findings concerning the effects of redundant information. Under the heading CF-C we observe that overall there was relatively little effect of redundant information in the matching task but that it tended to slow oddity responses relative to performance on the color-oddity task. On the other hand, the differences F-CF indicate that the four "color-biased" Ss responded faster to the redundant combination of color and form, usually significantly so, than they did to form alone. For these four Ss, speed of response to the redundant stimuli was intermediate between the speeds with which they responded to the two types of single-attribute stimuli. 5 was unbiased in 


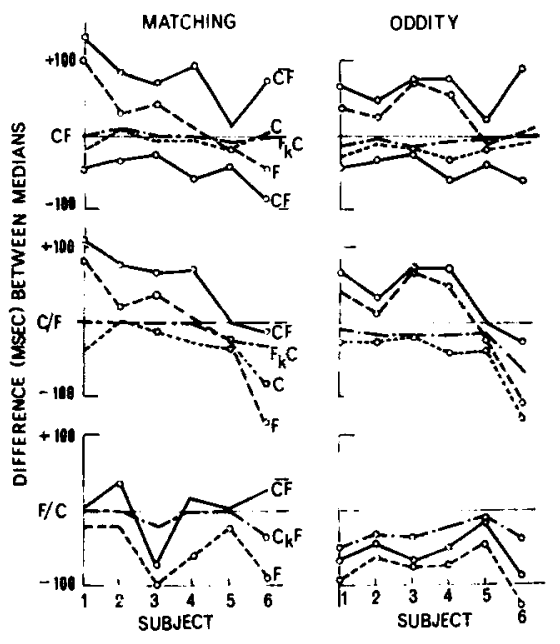

Fig. 1. Differences between medians of various model distributions and medians of empirical distributions from multiattribute tasks. Large circles represent differences significant at the .05 level.

terms of his response speeds to the single-attribute stimuli, but responded on the average about 10 to $20 \mathrm{msec}$ more slowly to redundant stimuli than to either type of single-attribute stimulus. Finally, S 6 responded to the redundant stimuli with approximately the same speed as he did to the slower of the two single-attribute stimuli, color in the case of matching and form in the case of oddity behavior.

Only one of the color-biased Ss was significantly slowed in matching color by the presence of irrelevant form information; but both the unbiased and the form-biased Ss were significantly slowed, as was S 4. All Ss were significantly slowed in choosing the odd color by the presence of irrelevant form information. All of the Ss were also slowed in both matching and oddity responding by the presence of irrelevant color information in the form task. This seemed to be just as true of the Ss who were not color-biased as it was of those who were. However, the column headed F/C.C/F shows that color-biased Ss were much slower in responding to form with irrelevant color than in responding to color with irrelevant form, while the unbiased and form-biased Ss were not.

\section{Analysis of Total Latency Distributions}

Cumulative relative frequency distributions were made, for each $S$ and each treatment, of the latencies of all initially correct responses, beginning with the third session. The analysis of mean scores had indicated that substantial decreases in latency occurred between the first and second and between the second and third sessions; but thereafter they remained approximately stable. A separate analysis was carried out on only the responses made on Panel $r 3$. These latency distributions showed less variability, of course, but also contained fewer responses. Since the conclusions to be drawn from the analysis of $\mathrm{r} 3$ responses were virtually identical, and since significance tests had slightly greater power when all responses were included, only the analysis of the total set of responses is reported here.

Figure 1 displays, for each of the three multiattribute tasks ( $\mathrm{CF}, \mathrm{C} / \mathrm{F}, \mathrm{F} / \mathrm{C})$, for matching and oddity task formats, and for each $S$, the success of the various models in predicting median response latency. This figure requires some comment, since it actually displays the results of 132 tests of model distributions in a very compact form. Each connected set of points is not a function, but the set of predictions made by a particular model distribution. It is expressed as a deviation between the median of the model distribution and the median of the empirical distribution. Predictions that are significantly too large or too small are shown as large open circles. Small points indicate predictions that were close enough to be acceptable (did not differ significantly from the empirical distribution), given the observed variability in latencies.

The CF distributions in both the matching and oddity tasks were in all cases significantly slower than the theoretical CF distribution and significantly faster than the $\overline{\mathrm{CF}}$ distribution. Most $S$ s were slower in responding to $\mathrm{CF}$ than they were to the fastest of their single-attribute stimuli. This result could be obtained if Ss were using their preferred attribute as relevant and rejecting the other attribute, so that the clearing model needed to be considered. Table 4 presents the values of the parameter $K$, the clearing time, that makes the medians of the $C F$ distribution and the $\mathrm{F}_{\mathrm{K}} \mathrm{C}$ distributions equal. Values greater than $300 \mathrm{msec}$ are considered implausible, since the total time to process the information and select a response was only about this value. In general, medians of the theoretical distributions tended to stabilize before $K$ reached 200 msec. Plausible values for $K$ were found for five of six matching distributions, but for none of the oddity distributions. However, in all cases when the $\mathrm{F}_{\mathrm{K}} \mathrm{C}$ model was applicable, the median for $\mathrm{CF}$ was between those for $\mathrm{C}$ and $F$ (see Fig. 1), so that a mixed strategy of selecting $\mathrm{C}$ or $\mathrm{F}$ is a viable alternative model.

In the $\mathrm{C} / \mathrm{F}$ matching task the latencies were consistently longer than those in the C distribution, although the differences were significant for only three Ss. The $\mathrm{F}_{\mathbf{K}} \mathrm{C}$ model gave good fits with some plausible value of $K$ for three of the four color-biased Ss. In the case of S 2, although the model appears to give a good fit, it is actually inappropriate, since the $\mathrm{F}_{\mathrm{K}} \mathrm{C}$ model produced consistently faster responses than those observed in the CF distribution, even when $K$ was set equal to 0 . Latencies from the $\mathrm{C} / \mathrm{F}$ oddity task were not well fit by any of the models tested. When a large value of $K$ was used ( $300 \mathrm{msec})$ the median of the $\mathrm{F}_{\mathrm{K}} \mathrm{C}$ distribution was consistently $10-30 \mathrm{msec}$ below the observed values for all Ss.

The $\mathrm{F} / \mathrm{C}$ matching distributions of four of six Ss could be fit by the $\mathrm{C}_{K} \mathrm{~F}$ model using plausible values of $\mathrm{K}$. Two $\mathrm{Ss}$ required significantly longer to perform this task then predicted by the $C_{K} F$ model with $\mathrm{K}=300 \mathrm{msec}$. In the oddity task, all Ss took longer than predicted by this model, and still longer than predicted by the $\overline{\mathrm{CF}}$ model.

\section{DISCUSSION}

Both the analysis of means of block medians and the analyses of total distributions are consistent in pointing to the following conclusions: (1) Most, but not all of the $S$ s responded significantly faster to color alone than to form alone. (2) The presence of irrelevant information tended to increase latencies. Increases were greater when the irrelevant attribute was one to which $\mathrm{Ss}$ responded rapidly. Increases in latencies by irrelevant

Tabie 4

Estimated Values in Milliseconds of the Clearing Time, $K$, that Makes the Medians of Empirical and Theoretical Distributions Equal

\begin{tabular}{|c|c|c|c|c|c|c|c|}
\hline & & \multicolumn{6}{|c|}{ Empirical Distribution } \\
\hline & & \multicolumn{3}{|c|}{ Matching } & \multicolumn{3}{|c|}{ Oddity } \\
\hline \multicolumn{2}{|c|}{ Subject } & CF & $\mathrm{C} / \mathrm{l}$ & $\mathrm{F} / \mathrm{C}$ & $\mathrm{Cl}^{2}$ & $\mathrm{C} / \mathrm{F}$ & $I: C$ \\
\hline 1 & $\mathrm{~F}$ & 70 & 166 & 125 & 300 & $>300$ & $>300$ \\
\hline 2 & $F$ & $*$ & $*$ & 83 & $>300$ & $>300$ & $>300$ \\
\hline 3 & $\mathrm{~F}$ & 35 & 60 & $>300$ & $>300$ & $>300$ & $>300$ \\
\hline 4 & M & 17 & 115 & 162 & $>300$ & $>300^{* *}$ & $>300$ \\
\hline 5 & $\mathbf{M}$ & $>300$ & $>300^{* *}$ & 80 & $>300$ & $>300^{* *}$ & $>300$ \\
\hline 6 & $\mathrm{M}$ & 145 & $>300^{* *}$ & $>300$ & 37 & $>300^{* * *}$ & $>300$ \\
\hline
\end{tabular}

* Empirical distribution faster than fastest single atribute distribution.

* Empirical distribution significantly slower than theoretical with $K$ set to $300 \mathrm{msec}(p<.01)$. 
Table 5

Differential Predictions of Inequalities by Certain Models. $S$ indicates a significant inequality in the predicted direction; $F$ indicates a significant inequality in the direction opposite to the prediction. The denominator shows the number of predictions attempted.

\begin{tabular}{|c|c|c|c|c|c|}
\hline & \multirow[b]{2}{*}{ Task } & \multicolumn{2}{|c|}{$\begin{array}{c}\text { Lefficient } 100 \\
\text { Bias } 0\end{array}$} & \multicolumn{2}{|c|}{$\begin{array}{l}\text { Efficient } 0 \\
\text { Bias } 100 \text { or } 0\end{array}$} \\
\hline & & Matching & Oddity & Matching & Oddity \\
\hline Paraliel 0 & $\begin{array}{l}\mathrm{Cl} \\
\mathrm{C} / \mathrm{F}\end{array}$ & $\begin{array}{l}0 / 12 \\
3 S / 6\end{array}$ & $\begin{array}{l}2 S / 12 \\
1 S / 6\end{array}$ & $\begin{array}{l}31 \div / 6 \\
31: / 6\end{array}$ & $\begin{array}{l}41: 6 \\
41: 6\end{array}$ \\
\hline
\end{tabular}

information were greater in the oddity task than in the matching task. (3) Redundant information did not significantly speed the responses of any $\mathrm{S}$. In the oddity task it slowed the responses of five out of six Ss. (4) Matching and oddity tasks appeared to involve different information-processing components, since they frequently showed different patterns of relationships.

One possibility that needs to be examined is that the differences in latencies between tasks were greatly influenced by differences in eye-movement patterns associated with them. This question has been investigated using three different practiced Ss, whose eye movements were recorded by electro-oculography during a single session identical to those described in this paper. Latencies did vary as the number of eye movements in a trial varied. However, when only those trials were included in which the most common number of movements occurred (two movements for two Ss, three for one S), the patterns of latency differences between tasks were strikingly similar to those observed when all trials were included. Thus, although variations in eye movements will undoubtedly influence our fine-grained analysis, they do not alter basic conclusions.

The failure to replicate the results of earlier experiments with regard to the effect of redundant information (Stone, 1969) could be due to any of threc differences in procedure: (1) the use of individual trial latencies as the dependent variable rather than time to complete a block of trials; (2) the location of the response directly on the stimulus in this experiment rather than $5 \mathrm{~cm}$ below it, as in earlier experiments; (3) the inclusion of irrelevant information in the test battery. The first alternative was examined by taking the mean for all Ss of the total time spent in selection responses in each block of trials. The medians of these block means were then compared. In every case but one (S2 matching), the median mean latency for $\mathrm{C}$ was shorter than it was for $\mathrm{CF}$. Therefore, this reason for the difference between experiments appears to be excluded. The other two possibilities require experimental investigation.
None of the several models proposed in the introduction is compatible with all of the data. Two kinds of predictions about multiattribute tasks were presented in Table 1: precise values for median latencies and certain inequalities. Evaluations of the precise predictions can only be made in terms of failures, since accepting the null hypothesis cannot be counted a success. Prediction of inequalities can yield either successes, when the inequality is significant in the predicted direction, or failures, if it is significant in the opposite direction. However, successes in predicting inequalities are of limited value in comparing models, since the E $100 \mathrm{~B} 100$ models made no such predictions, and the other models made identical predictions for most tasks. Table 5 presents the outcomes of predicted inequalities for only those comparisons where differential predictions were made. The POE100 BO model had a few successes, and the PO EO models were highly unsuccessful. These errors were the result of overestimates of the latencies by the model.

The numbers of median latencies that deviated significantly from their predicted values is shown in Table 6 . In this table, the E100 models tended to underestimate the time required, while the E0 model again overestimated. A mixed strategy in which some comparisons are terminated efficiently and some are not seems a tenable hypothesis.

The P0 E100 B0 model, which had only one failure, seems to have been overall the most successful. However, its predictions for two of the tasks involved the $C \cdot F$ distributions, which could not be precisely estimated. A kind of estimate of the median values for these distributions could be made by pooling data from an earlier experiment (Stone, 1970) with that reported here. In the previous study the number of comparison stimuli was varied so as to estimate slope and intercept of a function intended to separate the times for comparison operations from those for the selection and execution of the response. As Ss 1 to 5 of the present experiment were also $S s$ in the earlier one, it was possible to estimate the time that each required to process four form stimuli, eliminating the time for response execution. These estimates were then added to each S's mean latency in responding to color in the present experiment. When the values for $\mathrm{C} \cdot \mathrm{F}$ thus estimated were used to make predictions for the P0 E100 B0 model, the predicted values for both $C / F$ and $F / C$ were consistently larger by about 50 to $100 \mathrm{msec}$ than the observed values. It appears therefore that P0 E100 B0 may have difficulties that cannot be firmly demonstrated in this study.

The B100 models may be clearly rejected on the basis of their failure to predict the effects of irrelevant information. There remains for consideration the P100 E100 B0, which was obviously incorrect in its predictions about the $C F$ tasks and the $F / C$ oddity task. This model has the advantage of agreeing with work from other studies that indicate parallel processing to be possible; so it is worthwhile to consider if its failures in this experiment can be accounted for. The problem with the CF task is that, having assumed no biasing, we must predict CF. However, we found that the clearing model $\mathrm{F}_{\mathrm{K}} \mathrm{C}$, gave good predictions for the CF task. This model embodies a sort of second-level biasing-no control over what information reaches the decision channel, but a rejection of inappropriate information without completing the processing phase. If we permit the $\mathrm{CF}$ task to be approached as though it were a $\mathrm{C} / \mathrm{F}$

Table 6

Number of Significant Failures by the Several Models in Making Six Predictions for Each Task. + indicates that the observed latency was greater than predicted, - that it was less than predicted. $X$ indicates no precise test possible.

\begin{tabular}{|c|c|c|c|c|c|c|c|}
\hline & & & & & & $\begin{array}{l}\text { Eff } \\
\text { Bias }\end{array}$ & $\begin{array}{c}0 \\
\text { or } 0\end{array}$ \\
\hline & Task & $M$ & 0 & $\mathbf{M}$ & 0 & M & $\mathrm{O}$ \\
\hline & $\mathrm{Cl}$ & $2+$ & $3+$ & $6+$ & $6+$ & $6-$ & $6-$ \\
\hline Parallel 100 & $(/ /)$ & $3+$ & $6+$ & & & $4-$ & $4-$ \\
\hline & $1 / C$ & $4+$ & $6+$ & & $5+$ & $1-$ & $6+$ \\
\hline & $\mathrm{Cl}$ & $2+$ & $3+$ & $1+$ & & $\mathrm{X}$ & $X$ \\
\hline Parallel 0 & Cll: & $3+$ & $6+$ & $\mathrm{X}$ & $\mathrm{X}$ & $\mathrm{X}$ & $\mathrm{X}$ \\
\hline & $\mathrm{F} / \mathrm{C}$ & $4+$ & $6+$ & $\mathrm{X}$ & $X$ & $\mathrm{X}$ & $\mathrm{X}$ \\
\hline
\end{tabular}


task, we can eliminate 12 of the 17 failures observed in Table 6.

The remaining failures are the result of a consistent underestimation of the time required in the $\mathrm{F} / \mathrm{C}$ oddity task by the $\mathrm{C}_{\mathrm{K}} \mathrm{F}$ model. Figure 1 indicates a consistent but nonsignificant underestimation of latencies in the $\mathrm{C} / \mathrm{F}$ oddity task also. This difficulty could be related to some peculiarity of the oddity task, perhaps arising from the lack of a sample stimulus in the alternate frames. It is at least conceivable that Ss make use of the sample to get the information processing underway before the comparison stimuli are encountered. We are exploring this hypothesis using modified oddity tasks.

To recapitulate and summarize, three attributes of models for a visual search task were proposed for examination. The results obtained clearly favored efficient termination over exhaustive comparison of attributes. The alternative of a $100 \%$ biasing in selecting one attribute or the other was also excluded, although it appeared that the decision channel might be involved in a kind of biased use of received information. This conclusion was suggested by the failure of Ss to profit from redundant information. A serial-processing model would predict this failure, but it is unattractive in light of other experiments and also because of the overestimates of times it produces for the $\mathrm{C} / \mathrm{F}$ and $\mathrm{F} / \mathrm{C}$ tasks when data from this experiment are combined with those from an earlier study.

The model that best fits all of the present data and data from other studies is a modification of P100 E100 B0. That is, it involves parallel processing of input, efficient termination of comparison, and no selection of input to the decision channel. However, a kind of biasing appears to occur after admission to the decision process. The decision channel may be able to reject a specified attribute without processing it completely.

This strategy is an ideal from which Ss deviate on some trials. S $2, S 5$, and S 6 all deviated significantly in one way or another from the liberalized model, and their deviations were not eliminated by repeating the analyses using the 25 th percentile rather than the medians of their latency distributions (that is, were not due to inclusion of suboptimal trials). Two Ss appeared to be using a mix of E100 and E0 strategies, and one a mix of true $\mathrm{BO}$ in the CF matching.

Characterizing individual S's information-processing strategies must be regarded as a very uncertain enterprise at this time. Even in such a simple model space as the one proposed here, there will usually be fairly large regions of mixed strategies that can contain the observed data points. Nevertheless, the approach of comparing an individual's latencies with values from model distributions generated from his own empirical distributions seems to represent a step beyond the testing of inequalities.

\section{REFERENCES}

BILDLRMAN, I., \& CHECKOSKY, S. I\% Processing redundant information. Joumal of Experimental Psychology, in press.

EGETH, H. E. Parallel versus serial processes in multi-dimensional stimulus discrimination. Perception \& Psychophysics, 1966, 1 . 245-252.

IITTS, P. M. \& BIEDERMAN, I. S-R compatibility and information reduction. Journal of Experimental Psychology. 1965. $69,408-412$

HAWKINS, H. L. Parallel processing in complex visual discrimination. Perception \& Psychophysics, 1969, 5, 56-64.

HODGE, M. H. The influence of irrelcvant information upon complex visual discrimination. Journal of Fxperimental Psychology, 1959, 57, 1-5.

IMAI, S.. \& GARNER, W. R. Discriminability and preference for attributes in frec and constrained classification. Journal of Experimental Psychology, 1965, 69, 596-608.

MOOD, A. M. Introduction to the theory of statistics. New York: Mc(jraw-Hill, 1950.

MORIN, R. I., IFORRIN, B., \& ARCHLR. W. Information processing behavior: The role of irrelevant stimulus information. Journal of Experimental Psychology, 1961, 61, 89-96.

NIC KERSON, R. S. "Same"-"Different" response times with multi-attribute stimulus differences. Perceptual \& Motor Skills. 1967. 24, 543-554.

SIEGFL. S. Nonparametric statistic's for the beharioral sciences. New York: McGraw-Hill. 1956 .

STIRNBERG. S. Two operations in character recognition: Some evidence from reaction-time measurements. Perception \& Psychophysics, $1967,2,45-53$

STONE, G. C. Response latencies in matching and oddity performance: Effects of format, stimulus and demand variables. Perceptual \& Motor Skills. 1969, 29, 219-232.

STONE, G. C. Response latencies in human maiching-to-sample. Perception \& Psychophysics, 1970, 7, 197-205.

WINER, B. J. Statistical principles in experimental design. New York: McGraw-Hill. 1962.

\section{NOTES}

1. Any or all of these propertics could conceivably appear in a mix. Over a given collection of trials, for examplc. serial processing might be employed on $10 \%$ of the trials and parallel processing on $90 \%$. Channel selection might be effective on only $5 \%$ of trials or on $95 \%$. Thus. we are really dealing with a model space rather than with discrete models. The analyses in this study cannot explicitly consider mixed models.

2. Calculation of the theoretical distributions in this section are based on the familiar formulae from mathematical statistics for dealing with probabilities of jointly occurring events. Sec, for example, Mood (1950). The empirical frequency distributions are used to estimate probability distributions: For example, $F_{\mathrm{c}}(t)$ estimates the probability that the latency of a response to a color stimulus is less than or equal to a given value, $\operatorname{Pr}\left(l_{\mathrm{c}} \leqslant t\right)$. Similarly,

$$
f_{f}(t) \cong \operatorname{Pr}\left(l_{f} \leqslant t\right)
$$

Estimation of the smaller of a pair amounts to the generation of a probability distribution

$$
\begin{aligned}
\operatorname{Pr}\left(1_{(1} \leqslant t\right)= & \left.\operatorname{Pr}\left[\left(1_{c} \leqslant \mathrm{t}\right) \text { or } 1_{\mathrm{f}} \leqslant \mathrm{t}\right)\right] \\
= & \operatorname{Pr}\left(1_{\mathrm{c}} \leqslant \mathrm{t}\right)+\operatorname{Pr}\left(1_{\mathrm{f}} \leqslant \mathrm{t}\right) \\
& \cdots \operatorname{Pr}\left(1_{\mathrm{c}} \text { and } 1_{\mathrm{f}} \leqslant \mathrm{t}\right) .
\end{aligned}
$$

If $I_{c}$ and $I_{f}$ are independent,

$$
\operatorname{Pr}\left(1_{c} \text { and } 1_{f} \leqslant t\right)=\operatorname{Pr}\left(1_{c} \leqslant t\right) \times \operatorname{Pr}\left(1_{f} \leqslant t\right)
$$

1 an greatly indebted $10 \mathrm{Dr}$. Robert $\mathrm{M}$. Flashoff of the Research System Group in the Computer Center of the University of California at San Francisco for his assistance in these formulations, and to a grant from the National Institutes of Health (F- $-0122-08$ ) that made it possible.

3. If the functional relationship between $I_{0}$ and $1_{f}$ were monotonic and if the latency distributions werc normal, it would be possible to establish these bounds precisely. I am not able to show that they hold if either of these conditions is not met.

4. The $\mathrm{Cl}$ distribution cannot be calculated directly. Instead we obtain its complement (to a very close approximation) by

$$
\begin{aligned}
& 1-\bar{C} \mathrm{r}=\operatorname{Pr}\left(1_{\mathrm{c}}>\mathrm{t} \text { and } \mathrm{l}_{\mathrm{f}}>\mathrm{t}\right) \\
& \operatorname{Pr}\left(1_{c}>_{t}\right) \cong 1 \quad \operatorname{Pr}\left(1_{c} \leqslant t\right)=1 \quad C \\
& \operatorname{Pr}\left(1_{f}>t\right) \cong 1-\operatorname{Pr}\left(1_{f} \leqslant t\right)=1-F
\end{aligned}
$$

The rest follows as in Note 2.

5. Our theoretical predictions are made with respect to trials in which optimum information processing occurs. A difficult problem exists in identifying these trials within a distribution of latencies that also includes many trials that deviate from the optimum in a variety of unspecifiable ways. When the number of latencic observed is large. the primary mode or even the carliest mode might be the best single descriptor. The mean will systematically and often grossly overestimate the desired valuc. as it is seriously affected by a few long latencies. The inedian is usually close to the primary mode in our latency distribution, and it is reasonably stable in small yroups of latencies where the mode is not. Taking means of these medians does not reintroduce the bias that would occur if block means were used in the first place.

(Accepted for publication April 23.1970). 